\title{
Public awareness about the specialty of anesthesiology and the role of anesthesiologists: a national survey
}

\author{
Jae Jun Lee ${ }^{1}$, Nak Hun Lee ${ }^{1}$, Chong Min Park ${ }^{2}$, Sung Jin Hong ${ }^{2}$, Myoung-Hoon Kong ${ }^{3}$, \\ Kook Hyun Lee ${ }^{4}$, Jun Heum Yon ${ }^{5}$, and Sun Ok Song ${ }^{6}$ \\ Department of Anesthesiology and Pain Medicine, ${ }^{1}$ Hallym University School of Medicine, Chuncheon, ${ }^{2}$ Catholic University \\ College of Medicine, Seoul, ${ }^{3}$ Korea University College of Medicine, Seoul, ${ }^{4}$ Seoul National University College of Medicine, Seoul, \\ ${ }^{5}$ Inje university College of Medicine, Busan, ${ }^{6}$ Yeungnam University College of Medicine, Daegu, Korea
}

Background: The aims of this national survey were to determine the views of Korean people regarding the specialty of anesthesiology and the role of anesthesiologists and to consider the ways in which individual anesthesiologists and the Korean Society of Anesthesiologists inform the public.

Methods: This off-line national survey was conducted by a professional research organization to obtain exact and reliable data. The questionnaire included structured questions to identify perceptions of the specialty of anesthesiology and the role of anesthesiologists inside and outside the operating room, people's desire for explanation of anesthesia by anesthesiologists, and their opinion about the best way to raise awareness about anesthesia and anesthesiologists.

Results: Of the respondents, $25.2 \%$ did not know that anesthesiologists are in charge of anesthesia during surgery. Furthermore, even respondents who knew that had very little knowledge of anesthesiologists' actual roles inside and outside the operating room. Respondents wanted their anesthesiologist to inform them about their anesthesia.

Conclusions: The public's awareness regarding the role of anesthesiologists seems to be inadequate. To improve this awareness, in hospitals, each anesthesiologist should provide patients with more exact and detailed information. Simultaneously, the National Society of Anesthesiology should provide systematic information reflecting the public's thoughts. (Korean J Anesthesiol 2014; 66: 12-17)

Key Words: Anesthesia, Physician's role, Public opinion.

Received: April 5, 2013. Revised: 1st, April 29, 2013; 2nd, May 27, 2013; 3rd, May 30, 2013. Accepted: June 3, 2013.

Corresponding author: Sun Ok Song, M.D., Ph.D., Department of Anesthesiology and Pain Medicine, Yeungnam University College of Medicine, 317-1, Daemyeong-dong, Nam-gu, Daegu 705-717, Korea. Tel: 82-53-620-3362, Fax: 82-53-626-5275, E-mail: sosong@med.yu.ac.kr

(c) This is an open-access article distributed under the terms of the Creative Commons Attribution Non-Commercial License (http:// creativecommons.org/licenses/by-nc/3.0/), which permits unrestricted non-commercial use, distribution, and reproduction in any medium, provided the original work is properly cited. 


\section{Introduction}

Following great progress and advances in the field of anesthesia, anesthesiologists now play key roles in the intensive care unit, on the code team, and in the pain clinic, as well as in the operating room. However, there is little public exposure regarding the role of anesthesiologists in the various areas of hospitals. Furthermore, patients' awareness of the roles of anesthesiologists even in the operating room is limited, as proven by several worldwide studies [1-8].

Recently in Korea, the Korean Society of Anesthesiologists (KSA) has attempted to inform the public of the role and importance of anesthesiologists. Additionally, the KSA planned the first national public survey to investigate general knowledge of this topic. This off-line survey was conducted by a professional research organization to obtain exact and reliable data.

The aims of this survey were to determine the views of Koreans on the specialty of anesthesiology and the role of anesthesiologists and to explore the ways in which individual anesthesiologists and the KSA inform the public. This study also evaluated the difference in awareness between people who had undergone surgery under anesthesia and those who had not experienced surgery.
Table 1. Participants' Demographics

\begin{tabular}{lccc}
\hline $\begin{array}{c}\text { Number of } \\
\text { the public }\end{array}$ & $\begin{array}{c}\text { Group Y } \\
(\mathrm{n}=499)\end{array}$ & $\begin{array}{c}\text { Group N } \\
(\mathrm{n}=501)\end{array}$ & $\begin{array}{c}\text { Total } \\
(\mathrm{n}=1000)\end{array}$ \\
\hline Age & & & \\
$20 \mathrm{~s}$ & $120(24)$ & $155(30.9)$ & $275(27.5)$ \\
$30 \mathrm{~s}$ & $152(30.5)$ & $159(31.7)$ & $311(31.1)$ \\
$40 \mathrm{~s}$ & $90(18)$ & $98(19.6)$ & $188(18.8)$ \\
$50 \mathrm{~s}$ & $95(19)$ & $62(12.4)$ & $157(15.7)$ \\
$\geq 60 \mathrm{~s}$ & $42(8.4)$ & $27(5.4)$ & $93(9.3)$ \\
Gender & & & \\
Female & $304(60.9)$ & $278(55.5)$ & $582(58.2)$ \\
Male & $195(39.1)$ & $223(44.5)$ & $418(41.8)$ \\
Education level & & & \\
Middle school & $33(6.6)$ & $32(6.4)$ & $65(6.5)$ \\
High school & $190(38.1)$ & $178(35.5)$ & $368(36.8)$ \\
University & $257(51.5)$ & $273(54.5)$ & $530(53)$ \\
Higher & $19(3.8)$ & $18(3.6)$ & $37(3.7)$ \\
Occupation & & & \\
Student & $57(11.4)$ & $79(15.8)$ & $136(13.6)$ \\
Homemaker & $97(19.4)$ & $68(13.6)$ & $165(16.5)$ \\
Employed & $233(46.7)$ & $269(53.7)$ & $502(50.2)$ \\
Self-employed & $62(12.4)$ & $42(8.4)$ & $104(10.4)$ \\
Others & $50(10)$ & $43(8.6)$ & $93(9.3)$ \\
\hline
\end{tabular}

Data represent number of respondents (percentage). No significant differences were observed between the two groups.

Table 2. The Public's Awareness Regarding the Roles of Those Involved in Surgery with Anesthesia and the Roles in the Preoperative Period

\begin{tabular}{|c|c|c|c|}
\hline Number of the public & $\begin{array}{l}\text { Group Y } \\
(\mathrm{n}=499)\end{array}$ & $\begin{array}{l}\text { Group N } \\
(\mathrm{n}=501)\end{array}$ & $\begin{array}{c}\text { Total } \\
(\mathrm{n}=1000)\end{array}$ \\
\hline \multicolumn{4}{|l|}{ A. Basic awareness } \\
\hline 1. In your opinion, who is in charge of anesthesia for surgery? & \multicolumn{2}{|c|}{$\mathrm{P}<0.001^{*}, \dagger$} & \\
\hline a. Technician & $37(7.4)$ & $24(4.8)$ & $61(6.1)$ \\
\hline b. Surgeon & $51(10.2)$ & $25(5)$ & $76(7.6)$ \\
\hline c. Doctor specialized in anesthesia & $361(72.3)$ & $387(77.2)$ & $748(74.8)$ \\
\hline d. Nurse & $22(4.4)$ & $13(2.6)$ & $35(3.5)$ \\
\hline e. Don't know & $28(5.6)$ & $52(10.4)$ & $80(8)$ \\
\hline $\begin{array}{l}\text { 2. During an operation, what is the relationship between the surgeon } \\
\text { and the anesthesiologist? }\end{array}$ & \multicolumn{2}{|c|}{$\mathrm{P}=$ n.s. } & \\
\hline a. Under the surgeon's orders & $206(41.3)$ & $177(35.3)$ & $383(38.3)$ \\
\hline b. Under the anesthetic doctor's orders & $24(4.8)$ & $21(4.2)$ & $45(4.5)$ \\
\hline c. Each has different roles & $230(46.1)$ & $242(48.3)$ & $472(47.2)$ \\
\hline d. Don't know & $39(7.8)$ & $61(12.2)$ & $100(10)$ \\
\hline \multicolumn{4}{|l|}{ B. Roles during preoperative period } \\
\hline 1. Who determines whether the patient is fit for surgery (operability)? & \multicolumn{2}{|c|}{$\mathrm{P}=\mathrm{n} . \mathrm{s}}$. & \\
\hline a. Surgeon & $432(86.6)$ & $433(86.4)$ & $865(86.5)$ \\
\hline b. Doctor specialized in anesthesia & $55(11)$ & $54(10.8)$ & $109(10.9)$ \\
\hline c. Nurse & $7(1.4)$ & $3(0.6)$ & $10(1)$ \\
\hline d. Don't know & $5(1)$ & $11(2.2)$ & $16(1.6)$ \\
\hline 2. Who decides if a patient can eat before surgery? & \multicolumn{2}{|c|}{$\mathrm{P}=$ n.s. } & \\
\hline a. Surgeon & $350(70.1)$ & $358(71.5)$ & $708(70.8)$ \\
\hline b. Doctor specialized in anesthesia & $58(11.6)$ & $50(10)$ & $108(10.8)$ \\
\hline c. Nurse & $84(16.8)$ & $81(16.2)$ & $165(16.5)$ \\
\hline d. Don’t know & $7(1.4)$ & $12(2.4)$ & $19(1.9)$ \\
\hline
\end{tabular}

Data represent the number of respondents (percentage). $\mathrm{P}$ value is difference between group $\mathrm{Y}$ and group N. The questionnaire was written in Korean for participants and then translated into English for paper work. *Significant differences between group Y and group N. ${ }^{\dagger}$ This $\mathrm{P}$ value was analysed based on all variables. 


\section{Materials and Methods}

The survey was designed by the Korean Society of Anesthesiologists (KSA), to determine the national public's awareness of the specialty of anesthesiology and the role of anesthesiologists. The questionnaire was generated from a review of the literature on a similar topic [1-10] and modified according to local perceptions in the country. The questionnaire collected data on participant characteristics (age, gender, education level, occupation, and history of previous anesthesia exposure) and on perceptions of the specialty of anesthesiology and the role of anesthesiologists inside and outside the operating room. It also explored participants' desire for explanation of anesthesia by anesthesiologists and their opinion about how to raise awareness about anesthesia and anesthesiologists.

The survey was administered to 1000 members of the general public who had no specific ties to anesthesia or surgery and who were selected proportionally from each province according to the national population. This off-line national survey was conducted by a professional research organization in Korea, the Marketing Research Korea Co., Seoul, Korea.
All analyses were performed using SPSS software (ver. 12; SPSS, Chicago, IL, USA), and statistical significance was set at $\mathrm{P}$ $<0.05$. Statistical analyses were performed using Pearson's chisquared test or Fisher's exact test.

\section{Ethics statement}

Ethical approval for this study was not required as per Korean regulations.

\section{Results}

Of the 1000 survey participants, 499 (49.9\%) reported that they had had previous anesthetic surgical experience (Group Y), and 501 (50.1\%) reported no such prior experience (Group N). In group Y, 210 (42\%), 105 (21\%), 44 (9\%), and 85 (17\%) participants answered that they had received general anesthesia, spinal anesthesia, ambulatory sedative anesthesia, and other types, respectively. Fifty-five participants (11\%) answered "I don’t know."

Table 1 summarizes the demographic data of the two groups. Table 2, 3, and 4 show the results of the questionnaire about the

Table 3. The Public's Awareness Regarding the Roles in the Intraoperative Period

\begin{tabular}{|c|c|c|c|}
\hline Number of the public & $\begin{array}{l}\text { Group Y } \\
(\mathrm{n}=499)\end{array}$ & $\begin{array}{l}\text { Group N } \\
(\mathrm{n}=501)\end{array}$ & $\begin{array}{c}\text { Total } \\
(\mathrm{n}=1000)\end{array}$ \\
\hline $\begin{array}{l}\text { 1. Who controls vital signs such as blood pressure and heart rate } \\
\text { during an operation? }\end{array}$ & \multicolumn{2}{|c|}{$\mathrm{P}=$ n.s. } & \\
\hline a. Surgeon & $243(48.7)$ & $219(43.7)$ & $462(46.2)$ \\
\hline b. Doctor specialized in anesthesia & $97(19.4)$ & $93(18.6)$ & $188(18.8)$ \\
\hline c. Nurse & $152(30.5)$ & $179(35.7)$ & $333(33.3)$ \\
\hline d. Don’t know & $7(1.4)$ & $10(2.0)$ & $17(1.7)$ \\
\hline 2. Who administers the anesthetic drugs and fluids during an operation? & \multicolumn{2}{|c|}{$\mathrm{P}=$ n.s. } & \\
\hline a. Surgeon & $145(29.1)$ & $166(33.1)$ & $311(31.1)$ \\
\hline b. Doctor specialized in anesthesia & $86(17.2)$ & $82(16.4)$ & $168(16.8)$ \\
\hline c. Nurse & $260(52.1)$ & $237(47.3)$ & $497(49.7)$ \\
\hline d. Don’t know & $8(1.6)$ & $16(3.2)$ & $24(2.4)$ \\
\hline 3. Who estimates blood loss during an operation? & \multicolumn{2}{|c|}{$\mathrm{P}=\mathrm{n} . \mathrm{s}}$. & \\
\hline a. Surgeon & $335(67.1)$ & $316(63.1)$ & $651(65.1)$ \\
\hline b. Doctor specialized in anesthesia & $41(8.2)$ & $41(8.2)$ & $82(8.2)$ \\
\hline c. Nurse & $115(23)$ & $128(25.5)$ & $243(24.3)$ \\
\hline d. Don't know & $8(1.6)$ & $16(3.2)$ & $24(2.4)$ \\
\hline 4. Who transfuses blood when needed during an operation? & \multicolumn{2}{|c|}{$\mathrm{P}=\mathrm{n} . \mathrm{s}}$. & \\
\hline a. Surgeon & $222(44.5)$ & $233(46.5)$ & $455(45.5)$ \\
\hline b. Doctor specialized in anesthesia & $33(6.6)$ & $32(6.4)$ & $65(9.5)$ \\
\hline c. Nurse & $218(43.7)$ & $209(41.7)$ & $427(42.7)$ \\
\hline d. Don't know & $26(5.2)$ & $27(5.4)$ & $53(5.3)$ \\
\hline 5. Who resuscitates the patient during an operation? & \multicolumn{2}{|c|}{$\mathrm{P}=$ n.s. } & \\
\hline a. Surgeon & $459(92)$ & $457(91.2)$ & $916(91.6)$ \\
\hline b. Doctor specialized in anesthesia & $19(3.8)$ & $19(3.8)$ & $38(3.8)$ \\
\hline c. Nurse & $9(1.8)$ & $10(2)$ & $19(1.9)$ \\
\hline d. Don’t know & $12(2.4)$ & $15(3)$ & $27(2.7)$ \\
\hline
\end{tabular}

Data are number of respondents (percentage). P value is difference between group Y and group N. No significant differences were observed between the two groups. The questionnaire was written in Korean for participants and then translated into English for paper work. 
Table 4. The Public's Awareness Regarding the Roles in the Postoperative Period

\begin{tabular}{|c|c|c|c|}
\hline Number of the public & $\begin{array}{l}\text { Group Y } \\
(\mathrm{n}=499)\end{array}$ & $\begin{array}{l}\text { Group N } \\
(\mathrm{n}=501)\end{array}$ & $\begin{array}{c}\text { Total } \\
(\mathrm{n}=1000)\end{array}$ \\
\hline 1. Who makes sure the patient recovers smoothly after surgery? & \multicolumn{2}{|c|}{$\mathrm{P}=0.011^{*}$} & \\
\hline a. Surgeon & $51(10.2)$ & $63(12.6)$ & 114 (11.4) \\
\hline b. Doctor specialized in anesthesia & $148(29.7)$ & $185(36.9)$ & $333(33.3)$ \\
\hline c. Nurse & $279(55.9)$ & $227(45.3)$ & $506(50.6)$ \\
\hline d. Don’t know & $21(4.2)$ & $26(5.2)$ & $47(4.7)$ \\
\hline 2. In the recovery room, who manages the postoperative pain? & \multicolumn{2}{|c|}{$\mathrm{P}=0.006^{*}$} & \\
\hline a. Surgeon & $142(28.5)$ & $185(36.9)$ & $327(32.7)$ \\
\hline b. Doctor specialized in anesthesia & $52(10.4)$ & $65(13)$ & $117(11.7)$ \\
\hline c. Nurse & $283(56.7)$ & $230(45.9)$ & $513(51.3)$ \\
\hline d. Don’t know & $22(4.4)$ & $21(4.2)$ & $43(4.3)$ \\
\hline 3. In the recovery room, who is responsible for the patient's safe recovery? & \multicolumn{2}{|c|}{$\mathrm{P}=0.009^{*}$} & \\
\hline a. Surgeon & $143(28.7)$ & $158(31.5)$ & $301(30.1)$ \\
\hline b. Doctor specialized in anesthesia & $29(5.8)$ & $18(3.6)$ & $47(4.7)$ \\
\hline c. Nurse & $320(64.1)$ & $303(60.5)$ & $623(62.3)$ \\
\hline d. Don't know & $7(1.4)$ & $22(4.4)$ & $29(2.9)$ \\
\hline
\end{tabular}

Data represent the number of respondents (percentage). P value is difference between group Y and group N. * Significant differences between group Y and group N. The questionnaire was written in Korean for participants and then translated into English for paper work.

Table 5. In the Hospital, What is the Role of a Doctor Specialized in Anesthesia (Multiple Choices)?

\begin{tabular}{lcccc}
\hline \multicolumn{1}{c}{ Number of the public } & $\begin{array}{c}\text { Group } \mathrm{Y} \\
(\mathrm{n}=499)\end{array}$ & $\begin{array}{c}\text { Group N } \\
(\mathrm{n}=501)\end{array}$ & $\begin{array}{c}\text { Total } \\
(\mathrm{n}=1000)\end{array}$ \\
\hline & & P value & \\
1. Anesthesia for surgery in the operating room & $483(96.8)$ & $\mathrm{P}=$ n.s. & $495(98.8)$ & $978(97.8)$ \\
2. Emergency patient care in the emergency room & $102(20.4)$ & $\mathrm{P}=$ n.s. & $99(19.8)$ & $201(20.1)$ \\
3. Patients' care in the intensive care unit & $108(21.6)$ & $\mathrm{P}=$ n.s. & $94(18.8)$ & $202(20.2)$ \\
4. Local anesthesia for simple surgery in the OPD & $258(51.7)$ & $\mathrm{P}=$ n.s. & $243(48.5)$ & $501(50.1)$ \\
5. Resuscitation anywhere in the hospital & $31(6.2)$ & $\mathrm{P}=$ n.s. & $33(6.6)$ & $64(6.4)$ \\
6. Pain management in the pain clinic & $152(30.5)$ & $\mathrm{P}=$ n.s. & $135(26.9)$ & $287(28.7)$ \\
\hline
\end{tabular}

Data are number of respondents (percentage). P value is difference between group Y and group N. No significant differences were observed between the two groups. The questionnaire was written in Korean for participants and then translated into English for paper work.

Table 6. Public Requests for Pre-surgical Information About Anesthesia Provided by a Doctor Specialized in Anesthesia

\begin{tabular}{lccc}
\multicolumn{1}{c}{ Number of the public } & $\begin{array}{c}\text { Group Y } \\
(\mathrm{n}=499)\end{array}$ & $\begin{array}{c}\text { Group N } \\
(\mathrm{n}=501)\end{array}$ & $\begin{array}{c}\text { Total } \\
(\mathrm{n}=1000)\end{array}$ \\
\hline $\begin{array}{l}\text { 1. If you are to undergo an operation, do you want to receive an } \\
\text { explanation of anesthesia by a doctor specialized in anesthesia? }\end{array}$ & & & \\
a. Yes. I want detailed information & $337(67.5)$ & $309(61.7)$ & $646(64.6)$ \\
b. Yes, but less detailed information due to anxiety & $123(24.6)$ & $141(28.1)$ & $264(26.4)$ \\
c. No. & $15(3)$ & $16(3.2)$ & $31(3.1)$ \\
d. I don't know & $24(4.8)$ & $35(7)$ & $59(5.9)$ \\
\hline
\end{tabular}

Data are number of respondents (percentage). P value is difference between group Y and group N. No significant differences were observed between the two groups. The questionnaire was written in Korean for participants and then translated into English for paper work.

public's awareness regarding the preoperative, intraoperative, and postoperative specific roles of those involved in surgery with anesthesia, repectively. Table 5 shows the results to the question about the roles of doctors specialized in anesthesia (i.e., anesthesiologists) in the hospital (multiple choices). Table 6 shows the results of the public's request for information about anesthesia given by an anesthesiologist. Finally, Table 7 shows the public's perception of mass media presentations of the role of a doctor specialized in anesthesia during surgery, and their opinions on the best way to raise awareness about doctors specializing in anesthesia (multiple choice). 
Table 7. The Public's Experience of the Role of a Doctor Specialized in Anesthesia during Surgery in the Mass Media, and Their Opinion about How to Raise Awareness about Doctors Specialized in Anesthesia (Multiple Choice)

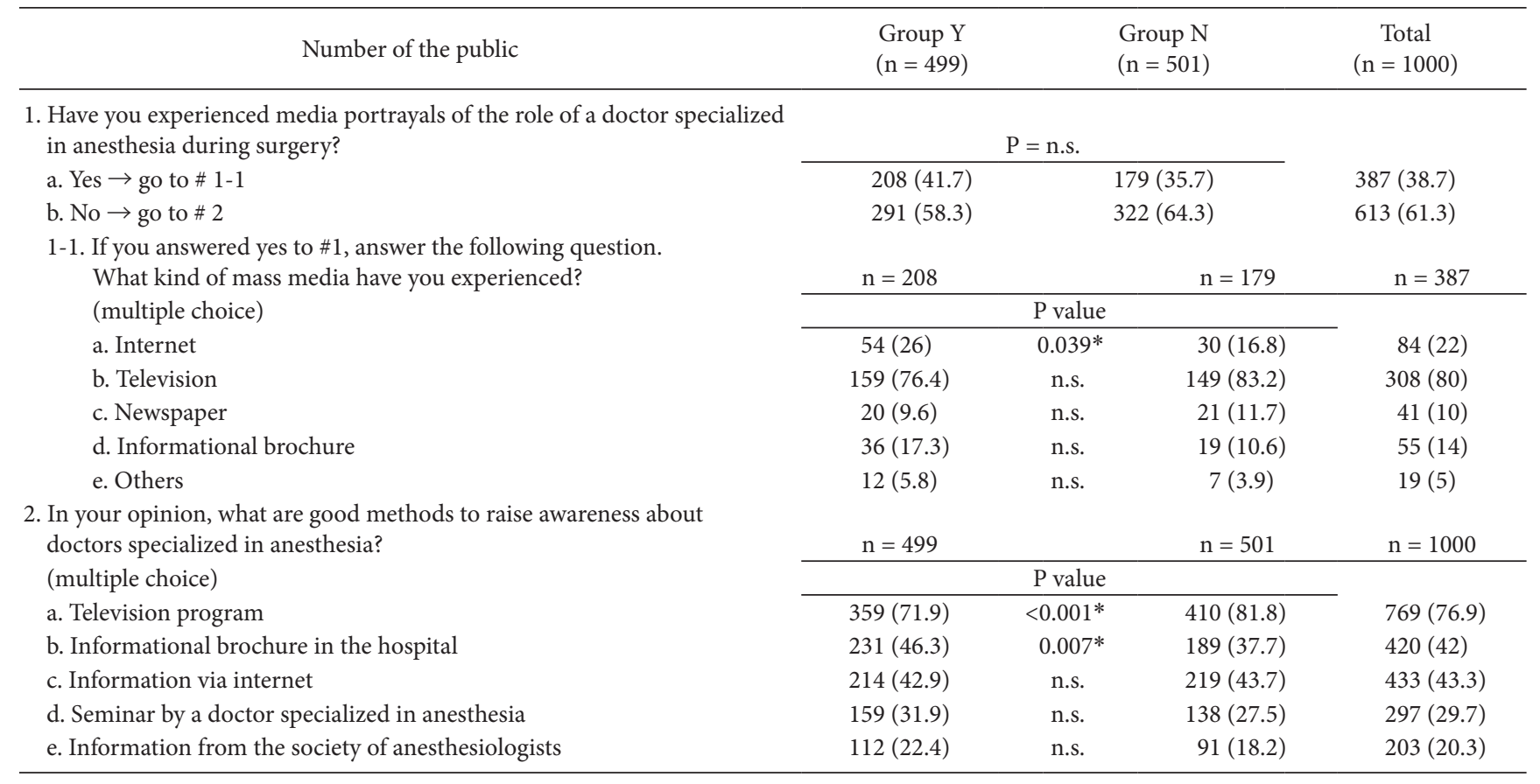

Data represent number of respondents (percentage). $\mathrm{P}$ value is difference between group $\mathrm{Y}$ and group $\mathrm{N}$. *Significant differences between group $\mathrm{Y}$ and group N. The questionnaire was written in Korean for participants and then translated into English for paper work.

\section{Discussion}

To our knowledge, this is the first national survey exploring general public awareness about the specialty of anesthesiology and the role of anesthesiologists. Although several surveys of this nature have been performed worldwide, most were performed in only one or a few hospitals [1-10], representing only patients' awareness in a limited area. In contrast, the results of our nationwide survey more accurately indicate general awareness. Furthermore, all previous surveys included patients awaiting elective surgery [1-10], with the result that the participants may have had an increased interest in anesthesia or surgery. However, the present survey targeted members of the general public who were not linked with anesthesia and were not awaiting surgery, likely yielding more objective results.

In the present study, $25.2 \%$ of respondents did not know that a doctor specialized in anesthesia who is the Korean expression for an anesthesiologists is in charge of anesthesia for surgery. Moreover, according to the detailed results, even respondents who knew that had very little knowledge of the actual roles and responsibilities of this doctor during anesthesia, and this level of knowledge was lower than that found by other surveys [1-10]. Regarding to the preoperative role of anesthesiologists, $86.5 \%$ and $70.8 \%$ of those surveyed thought that the surgeon decides the operability and NPO time, respectively. During surgery, $46.2 \%$ of them answered that the surgeon is in charge of moni- toring vital signs, despite the fact that this is actually one of most important roles of anesthesiologists. Strikingly, even the nurse was more likely to be selected as responsible for this role (33.3\%), and only $18.8 \%$ of people chose the anesthesiologist, considerably lower than in other surveys [1-10]. They also thought that estimation of blood loss and administration of transfusions were performed by the surgeon ( $65.1 \%$ and $45.5 \%)$, followed by the nurse $(24.3 \%$ and $42.7 \%)$. Only $8.2 \%$ and $9.5 \%$ of people chose the anesthesiologist for these roles. Also, the majority of participants (91.6\%) believed that the surgeon performed resuscitation during surgery. Although many of those surveyed believed that the anesthesiologist performed anesthesia for surgery, most of them seemed to have very little understanding of the province of anesthesia itself. Regarding the roles outside the operating room, 6-28.7\% of those surveyed were aware of anesthesiologists' other roles outside the operating room. On the other hand, 50.1\% thought that the anesthesiologist performed local anesthesia for a simple surgery in the OPD, indicating that the public has little understanding of the actual roles of an anesthesiologist.

In this survey, interestingly, those with prior anesthetic experience were more likely to believe that the surgeon takes responsibility for some intraoperative management and that nurses are in charge of recovery from anesthesia and managing the postoperative pain than were those who had no such prior experience. These results may be due to the fact that the surgeons explain the surgery for the patients before the opera- 
tion and visit them postoperatively, leading them to believe that the surgeon plays a key role in most areas of surgery, including anesthesia. Moreover, most patients directly contact the nurses if any problems arise in the immediate recovery. In contrast, most anesthesiologists visit the patients only one time preoperatively, although some studies have discussed that patient orientation in the pre-anesthetic visit is a way of publicizing the image of the professional and achieving patient recognition $[2,8,11]$. In this survey, $91 \%$ of respondents indicated a desire for information about their anesthesia from an anesthesiologist. Dedicated personal care including postoperative visits has been shown to be one of the most important factors affecting perception of the anesthesiologist. One study reported that perception of the anesthesiologist and satisfaction were significantly increased by a single postoperative visit by the anesthesiologist [12].

Our results showed that $38.7 \%$ of those surveyed experienced the roles of anesthesiologists via the mass media, and the results were similarly ordered in both groups (television $>$ internet $>$ informational brochure). Those surveyed differed in their opinion about the best way to raise awareness about anesthesia and the anesthesiologist depending in part on whether they had prior experience with anesthesia. The experienced public chose television program $>$ information brochure $>$ internet, but none of the experienced public chose television program $>$ internet $>$ information brochure. This difference may reflect the effects of information about anesthesia and the anesthesiologist given by brochure during admission for surgery. Recently, the KSA produced a simple but informative cartoon brochure that was distributed to hospitals nationwide, and both the patients' and anesthesiologists' response was very positive. Considering that the most frequent source of media awareness about anesthesiologists is television program, the public seems to prefer to be informed by methods already present in their daily lives. To provide information most effectively, the National Society of Anesthesiology of each country should consider its publics' thoughts and preferences, and periodic surveys every 5-10 years may be helpful to gather feedback from the public on this topic.

In conclusion, the Korean public has inadequate knowledge regarding the specialty of anesthesiology and the role of anesthesiologists inside and outside the operating room. To improve this awareness, in hospitals, each anesthesiologist should provide patients with more exact and detailed information and explain their anesthetic protocol by a postoperative visit as well as a preanesthetic visit. Simultaneously, the National Society of Anesthesiology should provide systematic information reflecting the public's thoughts and preferences.

\section{Acknowledgments}

The authors gratefully acknowledged the Korean Society of Anesthesiologists for helping with this survey.

\section{Declaration of Interest}

This study was sponsored by The Korean Society of Anesthesiologists. The KJA is the official journal of the Society.

\section{References}

1. Braun AR, Leslie K, Morgan C, Bugler S. Patients' knowledge of the qualifications and roles of anaesthetists. Anaesth Intensive Care 2007; 35: 570-4.

2. Hariharan S, Merritt-Charles L, Chen D. Patient perception of the role of anesthesiologists: a perspective from the Caribbean. J Clin Anesth 2006; 18: 504-9.

3. Baaj J, Takrouri MS, Hussein BM, Al Ayyaf H. Saudi patients' knowledge and attitude toward anesthesia and anesthesiologists--A prospective cross-sectional interview questionnaire. Middle East J Anesthesiol 2006; 18: 679-91.

4. Irwin MG, Fung SK, Tivey S. Patients' knowledge of and attitudes towards anaesthesia and anaesthetists in Hong Kong. Hong Kong Med J 1998; 4: 16-22.

5. Swinhoe CF, Groves ER. Patients' knowledge of anaesthetic practice and the rôle of anaesthetists. Anaesthesia 1994; 49: 165-6.

6. Tohmo H, Pälve H, Illman H. The work, duties and prestige of Finnish anesthesiologists: patients' view. Acta Anaesthesiol Scand 2003; 47: 664-6.

7. de Oliveira KF, Clivatti J, Munechika M, Falcão LF. What do patients know about the work of anesthesiologists? Rev Bras Anestesiol 2011; 61: 720-7.

8. Calman LM, Mihalache A, Evron S, Ezri T. Current Understanding of the patient's attitude toward the anesthetist's role and practice in Israel: effect of the patient's experience. J Clin Anesth 2003; 15: 451-4.

9. Huang Y, Yang K, Ren H, Luo A. A survey of elective surgical patients' attitudes toward anesthesia in PUMC hospital. Chin Med Sci J 2002; 17: 77-80.

10. Chew ST, Tan T, Tan SS, Ip-Yam PC. A survey of patients' knowledge of anaesthesia and perioperative care. Singapore Med J 1998; $39: 399-402$.

11. van Wijk MG, Smalhout B. A postoperative analysis of the patient's view of anaesthesia in a Netherlands' teaching hospital. Anaesthesia 1990; 45: 679-82.

12. Saal D, Heidegger T, Nuebling M, Germann R. Does a postoperative visit increase patient satisfaction with anaesthesia care? Br J Anaesth 2011; 107: 703-9. 